\title{
Neurobehavioral Alterations and Brain Creatine Kinase System Changes in Chronic Renal Failure Induced Male Wistar Rats: Impact of Erythropoietin Supplementation
}

\author{
Karthick N ${ }^{1}$, Alwin $\mathrm{D}^{3}$, Poornima KN ${ }^{1}$, Chitra $\mathrm{V}^{4}$, Saravanan $\mathrm{A}^{1}$, Balakrishnan $\mathrm{D}^{2}$ and Venkataraman $\mathrm{P}^{2 *}$
}

${ }^{1}$ Department of Physiology, SRM Medical College Hospital and Research Centre, SRM University, Kattankulathur - 603 203, Tamilnadu, India ${ }^{2}$ Department of Medical Research, SRM Medical College Hospital and Research Centre, SRM University, Kattankulathur - 603 203, Tamilnadu, India ${ }^{3}$ Department of Animal house, SRM Medical college Hospital and Research Centre, SRM University, Kattankulathur - 603203, Tamilnadu, India ${ }^{4}$ Department of Pharmacology, SRM College of pharmacy, SRM University, Kattankulathur - 603203, Tamilnadu, India

\begin{abstract}
Chronic renal failure (CRF) is a rapidly growing global health problem and it causes anaemia and cognitive impairment. Recombinant Human erythropoietin ( $\mathrm{rHu}$-Epo) has been a promising role in the management of anaemia in CRF subjects and it is well documented. It also shown as a remarkable neuroprotection in both cell cultures and in animal models. Creatine kinase (CK) plays a key role in energy metabolism and its activity found in cytoplasm of several human tissues; major sources of CK include skeletal muscle, myocardium and brain. Studies show brain energy metabolism is key to neuronal cell function and cognitive health. The aim of this study is to investigate the impact of rHu-Epo on CRF induced changes in CK system in serum and brain regions of experimental animals and to test its significance in neurobehavioral changes. Experimental design is divided into two phases to find out the variation between simultaneous and post rHu-Epo Treatment in CRF induced male wistar rats. At the end of 40 days, animals were sacrificed uniformly. In both phases, CK level in serum and selected brain regions such as cerebellum, cerebral cortex and hippocampus were determined by spectrophotometric method and hematological parameters (RBC, $\mathrm{Hb}, \mathrm{PCV}, \mathrm{MCV}, \mathrm{MCH}, \mathrm{MCHC}$ ) were also determined. In results, decreased creatine kinase activity in brain regions and its increased level in serum observed in CRF induced animals. Neurobehavioral changes and alterations in hematological parameters were also seen in CRF induced animals. Supplementation of rHu-Epo in both simultaneous and post treatment group reversed the CRF induced changes including neurobehavioral alterations, significantly. In this study, the protective role of Epo supplementation on CRF induced changes in CK system in both brain and serum and its correlation with neurobehavioral changes were seen along with its antianemic effect.
\end{abstract}

Keywords: Chronic renal failure; Neurobehavioral changes; Erythropoietin; Creatine kinase system

\section{Introduction}

Chronic renal failure (CRF) is a global health problem, that causes widespread organ damage and it is related to significant morbidity and mortality [1]. CRF encompasses a spectrum of disease, ranging from mild kidney damage which can be asymptomatic, to end stage disease, in which kidney function is impaired to such an extent that the retention of metabolic waste products, salt and water become potentially fatal [2]. CRF causes many complications such as anemia, pericarditis, cardiovascular disease, etc [3]. Many studies have shown that, CRF is associated with uremic encephalopathy and cognitive impairment. Cognitive tests demonstrate that there is objective evidence of moderate to severe cognitive impairment in $70 \%$ of patients with CKD [4]. Cognition refers to a range of brain functions that include the ability to learn and remember, think through and plan activities, concentrate and carry out tasks. In brain regions, the cerebral cortexes is the outer most part of brain and its many areas process sensory information or coordinate motor output necessary for control of movement. Cerebellum controls equilibrium and the coordination of fine motor movements, and may be involved in some cognitive functions. The hippocampus located in the middle of the brain, is a key structure associated with memory.

The uremic state of CRF is characterized by the retention of solutes that are toxic in high concentration such as urea, creatinine, parathyroid hormone, myoinositol, and beta macroglobulin [5]. Oxidative stress is an important event that has been related to the pathogenesis of diseases affecting the central nervous system. Studies have shown that the accumulation of toxic metabolites in renal failure may lead to excessive production of free radicals or depletion of antioxidant capacity [6]. Brain is highly sensitive to oxidative stress due to its high oxygen consumption, its high iron and lipid contents, especially polyunsaturated fatty acids, and the low activity of antioxidant defenses [7]. Studies show cognitive dysfunction increases in prevalence, due to increase in ROS in CKD severity [8].

Maintenance of energy homeostasis in the brain requires a distinct molecular circuitry which provides tight coupling between energy consumption and production during the performance of sensory, motor and cognitive tasks [9]. It is generally assumed that most energy required in the nervous system is provided in the form of adenosine triphosphate (ATP) by mitochondria, strategically located at sites of high demand, such as in axonal varicosities and dendrites. Organspecific enzymes are used in the assessment of tissue destruction in

*Corresponding author: Venkataraman P, Assistant professor, Department of Medical Research, SRM Medical College Hospital and Research Centre Kattankulathur - 603203, Tamilnadu, India, Tel: 09791745806; E-mail: venky_prabhu@hotmail.com

Received January 02, 2015; Accepted January 28, 2015; Published February 01,2015

Citation: Karthick N, Alwin D, Poornima KN, Chitra V, Saravanan A, et al. (2015) Neurobehavioral Alterations and Brain Creatine Kinase System Changes in Chronic Renal Failure Induced Male Wistar Rats: Impact of Erythropoietin Supplementation. J Bioequiv Availab 7: 074-081. doi:10.4172/jbb.1000218

Copyright: @ 2015 Karthick N, et al. This is an open-access article distributed under the terms of the Creative Commons Attribution License, which permits unrestricted use, distribution, and reproduction in any medium, provided the original author and source are credited. 
Citation: Karthick N, Alwin D, Poornima KN, Chitra V, Saravanan A, et al. (2015) Neurobehavioral Alterations and Brain Creatine Kinase System Changes in Chronic Renal Failure Induced Male Wistar Rats: Impact of Erythropoietin Supplementation. J Bioequiv Availab 7: $074-081$. doi:10.4172/jbb.1000218

various disease states, and creatine kinase (CK, EC 2.7.3.2) is used as a reliable marker in the assessment of myocardial, muscular and cerebral damage [10]. It is a crucial enzyme for high energy consuming tissues like the brain. It catalyses the reversible transfer of the phosphoryl group from phosphocreatine from adenosine diphosphate (ADP), to regenerate ATP and the transfer of high energy phosphate moiety is an important step in various processes in the body [11]. Study shows that CK is highly sensitive to free radicals, especially by the oxidation of thiol groups of its structure [12]. It is also known that a decrease in $\mathrm{CK}$ activity is associated with neurodegenerative pathways that result in neuronal death in brain ischemia [13], neurodegenerative diseases [14], bipolar disorder and other pathological states.

Erythropoietin (Epo) is a glycoprotein $(34 \mathrm{KDa})$ and it was originally recognized as a humoral mediator involved in the maturation and proliferation of erythroid progenitor cells but it is now appreciated for its neuroprotective effects on the central nervous system as well [15]. Epo is a standard therapy for the management of anemia in CRF. The clinical relevance for the use of Epo as a neuroprotective agent was enhanced when it was found to cross the blood - brain barrier after peripheral administration [16]. Epo was also shown to act as a tissue protective cytokine, especially within nervous tissue, kidney and cardiac muscle, and its receptor are widely distributed in variety of tissues [17]. Neuroprotection by Epo has been shown to associate with antiapoptosis, neuro-regeneration and anti-inflammation [18]. Several studies have indicated that it may protect neurons from glutamate toxicity by activating calcium channels and limiting the production of tissue injuring molecules such as reactive oxygen species, leading to the increased activity of antioxidant enzymes in neurons [19].

The significance of the brain and serum creatine kinase system and its correlation with neurobehavioral alterations in CRF induced experimental animals and the impact of Epo supplementation has not yet determined by earlier studies. In this context, the aim of this study was to assess the effect of Epo in both simultaneous and post treatment on creatine kinase status in serum and selected brain regions such as cerebellum, cerebral cortex and hippocampus of CRF induced animals.

\section{Materials and Methods}

\section{Animals}

A total of 48 male Wistar rats, weighing initially 100-150 g, were obtained and housed in the Animal House. They had free access to water and a feed composed of standard powder diet. The animals were maintained in controlled laboratory conditions of 12 hour dark/ light cycle, at a temperature of $22 \pm 1^{\circ} \mathrm{C}$. After 10 days of acclimatization, animals were randomly assigned to either the experimental groups or control group. All the animals were weighed alternative days throughout the study and water intake was also measured daily. This study was reviewed and approved by our Institutional Ethical committee.

\section{Chemicals}

Adenine was purchased from Sisco Researrch Laboratory (SRL), Mumbai, India. Epo was purchased from Serum institute of India, Pune. Standard powder diet was purchased from Veterinary Research Institute, Chennai, India.

\section{Experimental design}

Two phases were conducted to find out the difference between Simultaneous and Post treatment of Epo in CRF induced experimental animals. The dose of adenine $(0.75 \%)$ mixed diet for CRF induction was selected according to Ali et al. [1]. Dose and treatment procedure for Epo (100 IU/ kg body weight/ ip) was selected according to Bagnis et al. [20] and Lee et al. [21].

\section{Phase I}

A total of 24 male Wistar rats were used in this phase, and the animals were divided in to 4 groups (6 animals each): Group 1: Control animals without treatment, Group II: Animals which was given adenine $0.75 \%$ in feed for four weeks (28 days), Group III: Animals were treated by adenine $0.75 \%$ mixed diet for four weeks and simultaneous administration of Epo (100 IU per kg body weight) thrice weekly, in that period. Group IV: Epo alone has given (100 IU/ Kg bwt) thrice per week for four weeks. Simultaneously behavioral tests were conducted using rectangular and plus maze methods. All the animals in this phase were sacrificed after four weeks.

\section{Phase II}

A total of 24 male wistar rats were used in this phase, and the animals were divided in to 4 groups (6 animals each): Group I: Control animals without treatment, Group II: Animals which was given adenine $0.75 \%$ in feed for four weeks, Group III: In Epo post treatment group, animals were treated by adenine $0.75 \%$ mixed diet for four weeks for CRF induction. After fourth week, Epo (100 IU/ Kg bwt.) was administered for the next 12 days, daily once. Group IV: Epo alone has given (100 IU/ Kg bwt) thrice per week for four weeks. Simultaneously behavioral tests were conducted. All the animals in this phase were sacrificed after 40 days. Except the determination of creatine kinase activity in brain regions, the group III has two datas for all the parameters that is $3 \mathrm{a}$ and $3 \mathrm{~b}$ which indicates before (28th day) and after the treatment of Epo (40th day).

\section{Behavioral tests}

All the animals were trained for 2 days before drugs administration.

\section{Rectangular maze test}

In the treatment period, assessment of learning and memory can be effectively done by this method. The maze consists of completely enclosed rectangular box with an entry and reward chamber appended at opposite ends. The box is partitioned with wooden slots into blind passages leaving just twisting corridor leading from the entry to the reward chamber. Animals were trained prior to the experiment by familiarizing with the rectangular maze for a period of $10 \min$ for $2 \mathrm{~h}$. Well-trained animals were taken for the experiment. Transfer latency (time taken to reach the reward chamber) was recorded. For each animal, four readings were taken and the average is taken as learning score (transfer latency) for that animal. Lower scores of assessment indicate efficient learning while higher scores indicate poor learning in animals [14]. The time taken by the animals to reach the reward chamber from the entry chamber was noted on day $1,7,14,21,28,34$ and 40 .

\section{Plus maze}

The elevated plus maze (EPM) apparatus is a well-known and widely used model to assess anxiety-related behavior in rodents. The elevated plus-maze consists of two open arms and two arms that are enclosed by high walls. The open arms are perpendicular to the closed arms, with the four arms intersecting to form the shape of a plus sign. The plus-maze is usually elevated approximately $50 \mathrm{~cm}$. above the floor. Security is provided by the closed arms whereas the open arms offer exploratory value. Therefore, one would expect anxious animals to spend less time in the open arms than those that are less fearful [22]. 
Citation: Karthick N, Alwin D, Poornima KN, Chitra V, Saravanan A, et al. (2015) Neurobehavioral Alterations and Brain Creatine Kinase System Changes in Chronic Renal Failure Induced Male Wistar Rats: Impact of Erythropoietin Supplementation. J Bioequiv Availab 7: $074-081$. doi:10.4172/jbb.1000218

Environmental temperature was maintained equal to the temperature measured in the housing room. Each animal was placed at the center of the elevated plus-maze with its head facing the open arms and allowed to freely explore for $5 \mathrm{~min}$. After each observation, the EPM was cleaned with ethyl alcohol (10\%) to remove scent cues left from the preceding subject. During this 5 min experiment, the behavior of the animal was recorded as Percent time spent in open arm (OA), Number of entries in open $\operatorname{arm}(\mathrm{EOA})$, Percent time spent in closed $\operatorname{arm}(\mathrm{CA})$, Number of entries in Closed arm(ECA), Percent time spent in Centre, Stretched Attend Posture (SAP), Rearing, Grooming, Defecation, Head Dips.

\section{Sample collection and preparation}

Blood samples were immediately collected by Retro orbital bleeding method, both without anticoagulant and with EDTA. Samples without EDTA were centrifuged at $5000 \mathrm{rpm}$ for 20 minutes and the samples were stored in $-70^{\circ} \mathrm{C}$ until analysis. Blood samples with EDTA were used for the analysis of blood parameters such as RBC, $\mathrm{Hb}$ and Hematocrit (PCV) using automated cell counter and centrifugation. Based on these values $\mathrm{MCV}, \mathrm{MCH}$ and $\mathrm{MCHC}$ were calculated. Serum samples stored in $-70^{\circ} \mathrm{C}$ were used for the analysis of biochemical parameters such as blood urea nitrogen (BUN), serum creatinine to confirm the induction of CRF. Serum creatine kinase level was also determined.

\section{Tissue and homogenate preparation}

The animals were sacrificed by cervical dislocation and the brain regions were immediately removed, washed in ice-cold physiological saline repeatedly and carefully cleaned of adherent fat and connective tissue. Using Tris- $\mathrm{HCl}$ buffer $(0.1 \mathrm{M}, \mathrm{pH} 7.4), 10 \%$ homogenate was prepared and the supernatant was used for determining the brain creatine kinase activity.

\section{Determination of creatine kinase (CK) activity}

The activity of creatine kinase was assayed spectrophotometrically in serum and brain regions by standard procedure [23]. CK was measured in a $60 \mathrm{mM}$ Tris-Hcl buffer, $\mathrm{pH} 7.5$, containing $7 \mathrm{mM}$ phosphocreatine, $9 \mathrm{mM} \mathrm{MgSO}_{4}$, and approximately 1 microgram protein in a final volume of $0.13 \mathrm{~mL}$. After $20 \mathrm{~min}$ pre-incubation at $37^{\circ} \mathrm{C}$, the reaction was started by the addition of 0.42 micro mol ADP (2.8 mM final concentration). The reaction was stopped after the incubation time was chosen to assure linearity of the enzymatic reaction. Appropriate controls were carried out to measure the spontaneous hydrolysis of phosphocreatine. The creatine formed was estimated according by calorimetric measurement [24]. The colour was developed by the addition of $0.1 \mathrm{~mL} 2 \%$ alpha - naphtol and $20 \mathrm{~min}$ at $540 \mathrm{~nm}$. The creatine kinase activity in brain regions was expressed as $\mu \mathrm{mol}$ of creatine formed $/ \mathrm{min} . / \mathrm{mg}$ protein. The creatine kinase level in serum was expressed as IU/l.

\section{Statistical analysis}

The statistical analysis of the results was conducted using SPSS version 21 , the independent $t$ test and the one way analysis of variance (ANOVA) followed by Turkey's multiple comparison tests. The probability level less than 0.05 were considered as significant. Results were expressed as mean \pm SEM.

\section{Results}

Figure 1 and 2, shows the impact of Epo supplementation on $\mathrm{CRF}$ induced changes in BUN and Serum creatinine levels. The BUN and serum creatinine levels were significantly increased in CRF induced groups when compared to control ( $p$ value $<0.001$ ). In both simultaneous and Post treatment of Epo, the levels were retrieved.

Table 1, shows the impact of simultaneous and post Epo supplementation on hematological parameters such as RBC, Hb, PCV in CRF induced animals. There is a significantly decreased levels of above mentioned hematological parameters were observed in CRF induced animals. The levels were retrieved after both the simultaneous and post Epo supplementation. The blood indices such as $\mathrm{MCV}, \mathrm{MCH}$ $\mathrm{MCHC}$ also show significant changes in all the groups. Along with this, we also observed significant increased levels of RBC, $\mathrm{Hb}$ and PCV in Epo alone supplemented group.

Figure 3 shows the impact of Epo supplementation on CRF induced changes in the level of serum creatine kinase. A significant increase in serum creatine kinase was observed in CRF induced animals. The simultaneous and post treatment of Epo in CRF induced animals reversed the changes, significantly. Figure 4 shows the effect of Epo supplementation on CRF induced changes in creatine kinase activity in selected brain regions such as cerebellum, cerebral cortex and hippocampus. The activity of creatine kinase was decreased significantly in all the brain regions. The simultaneous administration of Epo in CRF induced animals restored the activity of creatine kinase, significantly. The post treatment also restores the same.

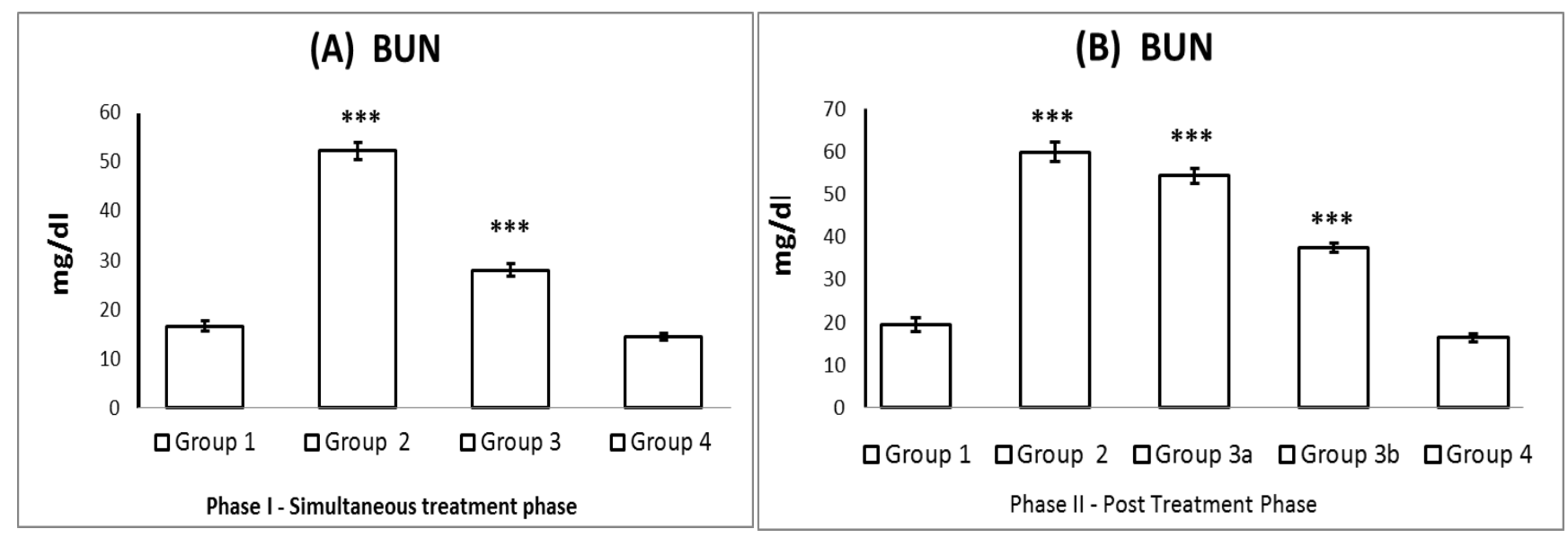

Figure 1: Blood Urea Nitrogen (BUN) levels in CRF induced and EPO treated animals in both (A) - Simultaneous treatment phase and (B) - Post treatment phase. Results are expressed as mean \pm SEM of 6 animals in each group; ${ }^{* * *} P<0.001$ 
Citation: Karthick N, Alwin D, Poornima KN, Chitra V, Saravanan A, et al. (2015) Neurobehavioral Alterations and Brain Creatine Kinase System Changes in Chronic Renal Failure Induced Male Wistar Rats: Impact of Erythropoietin Supplementation. J Bioequiv Availab 7: 074-081. doi:10.4172/jbb.1000218
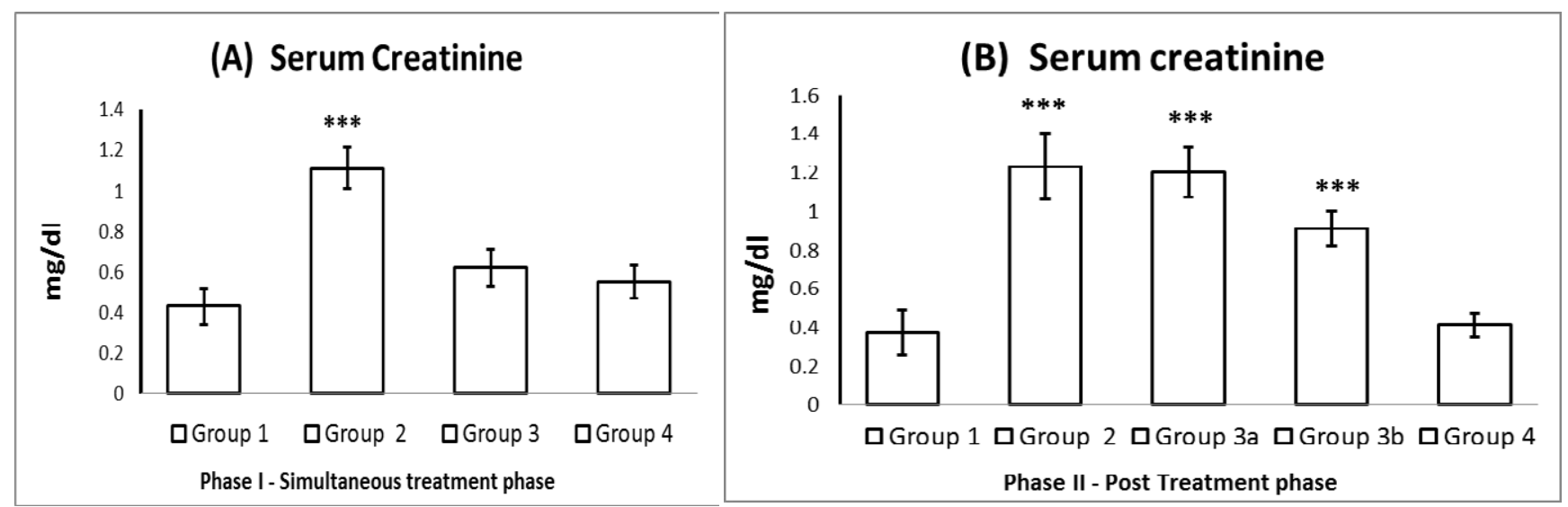

Figure 2: Serum Creatinine levels in CRF induced and EPO treated animals in both (A) - Simultaneous treatment phase and (B) - Post treatment phase. Results are expressed as mean \pm SEM of 6 animalsin each group; ${ }^{\star \star *} \mathrm{P}<0.001$.

Phase I:

\begin{tabular}{|c|c|c|c|c|}
\hline Parameters & Group 1 & Group 2 & Group 3 & Group 4 \\
\hline RBC (millions/cumm) & $7.05 \pm 0.52$ & $4.42 \pm 0.31^{* *}$ & $7.3 \pm 0.43 \mathrm{NS}$ & $11.3 \pm 0.88^{* * *}$ \\
\hline $\mathrm{HB}(\mathrm{g} \%)$ & $13.13 \pm 0.62$ & $6.65 \pm 0.51^{* * *}$ & $10.2 \pm 0.25^{*}$ & $17.6 \pm 1.31^{* * *}$ \\
\hline PCV (\%) & $43.08 \pm 2.73$ & $27.33 \pm 1.80^{* \star *}$ & $37.83 \pm 2.15 \mathrm{NS}$ & $58.50 \pm 2.36^{\star \star}$ \\
\hline $\operatorname{MCV}(f l)$ & $60.92 \pm 1.29$ & $61.78 \pm 1.27 \mathrm{NS}$ & $51.80 \pm 2.56^{*}$ & $54.76 \pm 1.02 \mathrm{NS}$ \\
\hline $\mathrm{MCH}(\mathrm{pg})$ & $16.95 \pm 0.69$ & $13.81 \pm 0.19^{* *}$ & $14.15 \pm 0.76^{* *}$ & $16.61 \pm 0.32 \mathrm{NS}$ \\
\hline $\mathrm{MCHC}(\mathrm{g} / \mathrm{dl})$ & $28.62 \pm 0.74$ & $21.27 \pm 0.81^{\star \star \star}$ & $27.37 \pm 0.88 \mathrm{NS}$ & $35.82 \pm 0.70^{*}$ \\
\hline
\end{tabular}

Phase II:

\begin{tabular}{|c|c|c|c|c|c|}
\hline Parameters & Group 1 & Group 2 & Group 3a & Group 3b & Group 4 \\
\hline RBC (millions/cumm) & $7.58 \pm 0.46$ & $3.87 \pm 0.18^{* * *}$ & $4.48 \pm 0.32^{* *}$ & $6.53 \pm 0.41 \mathrm{NS}$ & $12.3 \pm 0.71^{* * *}$ \\
\hline $\mathrm{Hb}(\mathrm{g} \%)$ & $12.63 \pm 0.52$ & $6.08 \pm 0.38^{* * *}$ & $5.96 \pm 0.30^{* * *}$ & $10.85 \pm 0.32 \mathrm{NS}$ & $18.6 \pm 1.11^{* * *}$ \\
\hline PCV (\%) & $46.00 \pm 2.29$ & $24.33 \pm 1.49^{* * *}$ & $27.50 \pm 1.17^{* * *}$ & $35.17 \pm 1.35^{\star *}$ & $56.27 \pm 2.15^{\star *}$ \\
\hline MCV (fl) & $57.92 \pm 1.34$ & $62.09 \pm 1.79 \mathrm{NS}$ & $62.16 \pm 2.37 \mathrm{NS}$ & $54.47 \pm 2.43 \mathrm{NS}$ & $52.39 \pm 1.92 \mathrm{NS}$ \\
\hline $\mathrm{MCH}(\mathrm{pg})$ & $17.45 \pm 0.69$ & $12.97 \pm 0.24^{\star *}$ & $13.52 \pm 0.72^{* \star *}$ & $15.18 \pm 0.45^{*}$ & $24.31 \pm 0.52^{\star *}$ \\
\hline $\mathrm{MCHC}(\mathrm{g} / \mathrm{dl})$ & $29.85 \pm 0.24$ & $22.33 \pm 0.67^{\star * \star}$ & $21.73 \pm 0.74^{* * *}$ & $34.25 \pm 0.88^{*}$ & $38.12 \pm 0.65^{\star *}$ \\
\hline
\end{tabular}

Table 1: Effect of EPO on CRF induced changes in hematological parameters in both phase I and phase II. Results are expressed as mean \pm SEM of 6 animals for each group; * $\mathrm{P}<0.05$, ${ }^{* *} \mathrm{P}<0.01$, ${ }^{* *} \mathrm{P}<0.001$, NS - Not Significant; RBC - Red blood cells, HB - hemoglobin, PCV - packed cell volume, MCV - mean corpuscular volume, $\mathrm{MCH}-$ Mean corpuscular hemoglobin, $\mathrm{MCHC}$ - Mean corpuscular hemoglobin concentration.

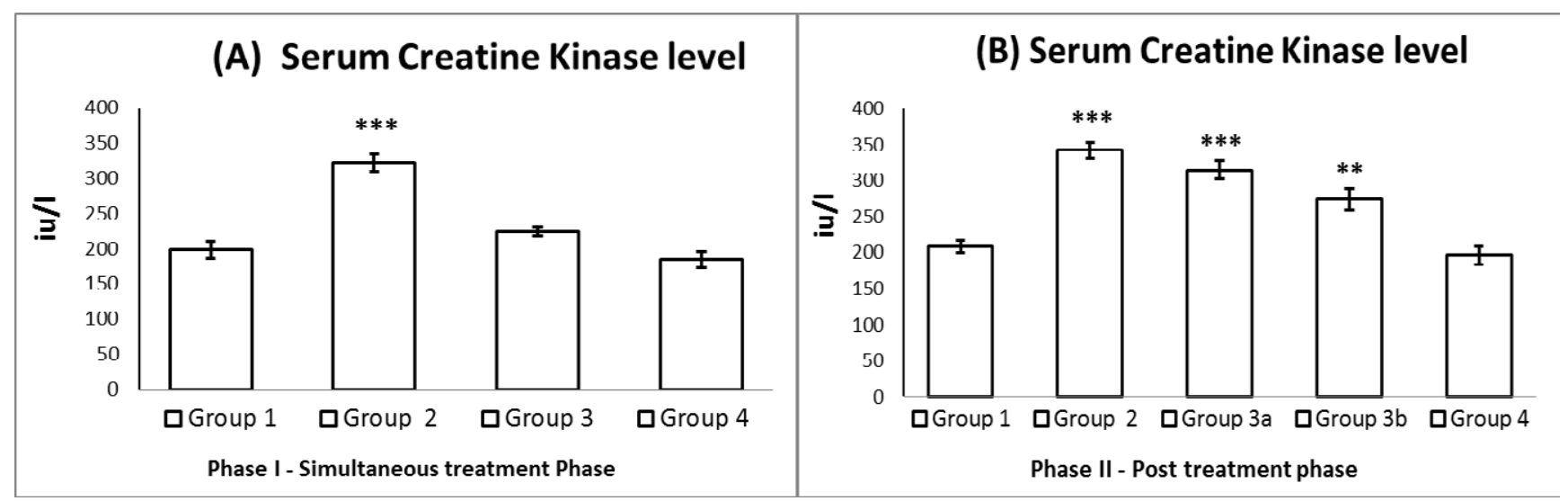

Figure 3: Serum Creatine kinase levels in CRFinduced and EPO treated animals in both (A) - Simultaneous treatment phase and (B) - Post treatment phase. Results are expressed as mean \pm SEM of 6 animalsin each group; ${ }^{* *} P<0.01,{ }^{* * *} P<0.001$.

Figure 5 shows the impact of Epo supplementation on behavioral changes in CRF induced animals by using rectangular maze method. The Transfer latency period of control and treated animals was assessed to find out the learning and memory function. The CRF induced animals show significant increase in transfer latency period on 28 th day compared withday 0 of the same group as well as with 
Citation: Karthick N, Alwin D, Poornima KN, Chitra V, Saravanan A, et al. (2015) Neurobehavioral Alterations and Brain Creatine Kinase System Changes in Chronic Renal Failure Induced Male Wistar Rats: Impact of Erythropoietin Supplementation. J Bioequiv Availab 7: $074-081$. doi:10.4172/jbb.1000218
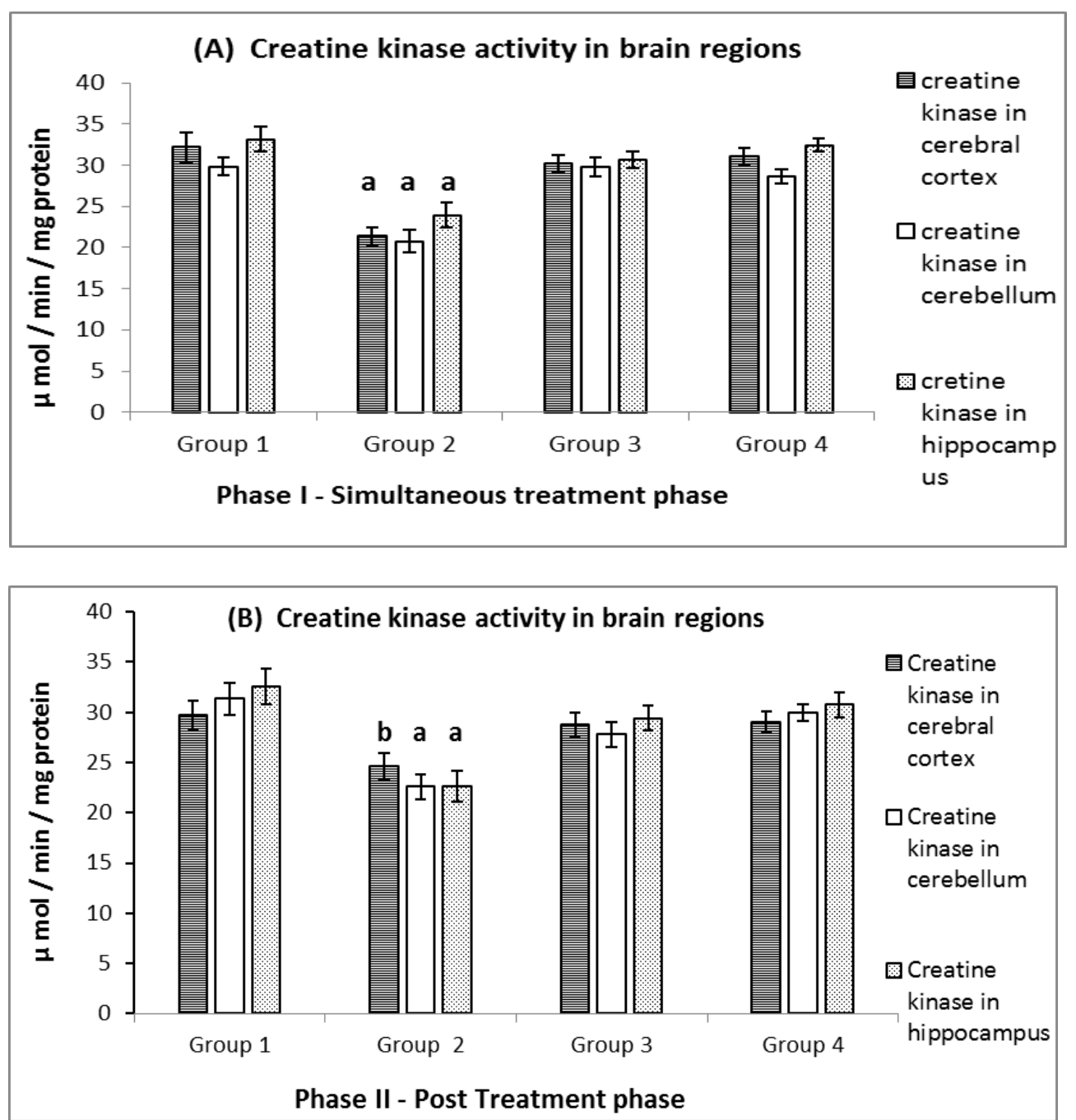

Figure 4: Brain creatine kinase activity in CRFinduced and EPO treated animals in both (A) - Simultaneous treatment phase and (B) - Post treatment phase. Results are expressed as mean \pm SEM of 6 animalsin each group; (a) $-\mathrm{P}<0.001$, (b) $-\mathrm{P}<0.01$.

the control group. We observed that there is no significant change in that period of simultaneous Epo treated group when compared to control. But we also observed that the regaining of memory during post treatment of Epo, where there is a gradual increase in transfer latency till 28th day. After that, the latency period decreased gradually due to the post administration of Epo till $40^{\text {th }}$ day. This indicates memory enhancing capacity of the Epo in CRF induced animals. The Epo alone supplemented animals showed significant decreased transfer latency period when compared to control in day 28.

Table 2 represents the effect of Epo supplementation on behavioral changes by using the plus maze to assess the anxiety level of the animals. In CRF induced animals, increases in anxiety levels were observed by various parameters. In both simultaneous and post Epo treatment groups, the anxiety levels were slightly reversed but not significantly, when compared with control group. In Epo alone treated animals, increased anxiety levels were observed; it may be because of the regular injections.

\section{Discussion}

CRF is characterized by retention of solutes that are toxic in high concentration such as urea, creatinine etc. [5]. In this study, serum creatinine and blood urea nitrogen were increased in adenine induced CRF animals. Studies have shown that, the accumulation of toxic metabolites in renal failure may lead to excessive production of free radicals or depletion of antioxidant capacity. Oxidative modification of brain proteins may disturb neuronal functions by decreasing activities of key metabolic enzymes and affecting cellular signaling systems [6]. Creatine kinase is a crucial enzyme for high energy consuming tissues like brain, skeletal muscle and heart. This enzyme works as a buffering system of cellular ATP levels, playing a central role in energy metabolism [25]. Studies show creatine kinase is sensitive to oxidative damage [17] and might be one of the targets for reactive oxygen species in the brain in neurodegenerative disease [9]. In this study decreased creatine kinase activity was observed in all the selected brain regions such as cerebellum, cerebral cortex and hippocampus of adenine induced CRF animals (Fig. 4) along with significant neurobehavioral changes (Table 2 and Figure 5). An increase in serum creatine kinase level and a corresponding decrease in brain creatine kinase in CRF induced animals is due to the leakage of this enzyme from the corresponding tissues into the blood stream [26]. 
Citation: Karthick N, Alwin D, Poornima KN, Chitra V, Saravanan A, et al. (2015) Neurobehavioral Alterations and Brain Creatine Kinase System Changes in Chronic Renal Failure Induced Male Wistar Rats: Impact of Erythropoietin Supplementation. J Bioequiv Availab 7: $074-081$. doi:10.4172/jbb.1000218
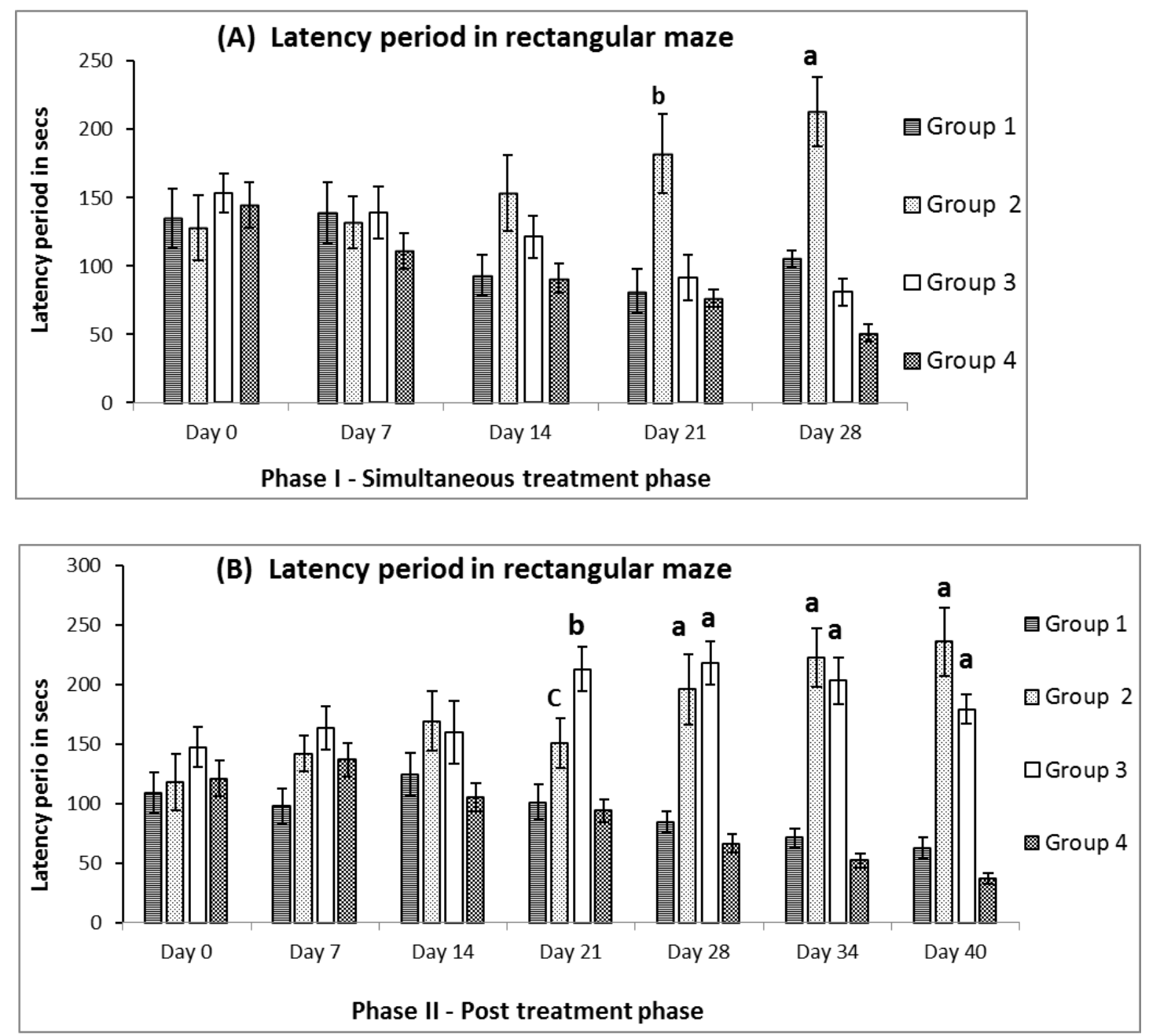

Figure 5: Latency period of rectangular maze in CRF induced and EPO treated animals in both (A) - Simultaneous treatment phase and (B) - Post treatment phase. Results are expressed as mean \pm SEM of 6 animalsin each group; (a) $-\mathrm{P}<0.001$, (b) $-\mathrm{P}<0.01$, (c) $\mathrm{P}<0.05$.

Uremic encephalopathy is an organic brain syndrome which occurs in patients with CKD and it is one of the important complications [27]. In uremic animals and invitro studies, it has been noticed that the intermediary metabolism is affected with increased levels of creatine phosphate, ATP, glucose and decreased levels of monophosphate, ADP and lactate. These biochemical changes are associated with a reduced metabolic rate of the brain and decrease in cerebral oxygen consumption [28]. Compounds accumulating in uremic serum with molecular mass from 300-5000 Da are called uremic middle molecules. Studies have shown that, 'middle molecules' are the toxins that underlie the development of neurological dysfunction in CKD [29]. Altered mental state reflects the toxic effect of uremia in the brain and contributes largely to the morbidity and mortality in patients with renal failure [30]. It is also known that a diminution of creatine kinase activity may potentially impair energy homeostasis, contributing to cell death [10].

Anemia is also a frequent complication associated with renal failure [31]. Accumulation of uremic toxins, excessive toxic storage of aluminium in the bone marrow [32], blood loss and premature erythrocyte destruction have been frequently associated with anemia in renal failure patients [33]. Anaemia has a negative impact on cognitive function and quality of life [34]. In CKD, both anemia and uremic encephalopathy contributes to cognitive impairment. Uremic animals have decreased cognition especially in the area of memory and executive function [4]. In this study anemia was observed in CRF induced animals by the confirmation of reduced hematological parameters such as RBC, Hb and Packed Cell Volume (PCV) (Table 1). Along with this, significant neurobehavioral changes were seen in CRF induced animals. Based on this context, neurobehavioral changes in CRF induced animals is due to changes in different factors such as anemic state, accumulation of uremic toxins and decreased brain creatine kinase activity.

Epo is used routinely to treat anemia in CKD. In this study, changes in hematological parameters induced by CRF were retrieved after simultaneous and post treatment of Epo (Table 1). Studies have shown that along with the level of $\mathrm{Hb}$, cognitive function also improves $[35,36]$. Epo exerts a remarkable neuroprotection in both cell cultures and in animal models [37,38]. In mice, Epo treatment improves hippocampus dependent memory by modulating plasticity, synaptic connectivity and activity of memory related neuronal networks [39]. Exogenous administration of Epo in rodents, rescued hippocampal CA1 neurons from lethal ischemic damage, and prevented ischemia- 
Citation: Karthick N, Alwin D, Poornima KN, Chitra V, Saravanan A, et al. (2015) Neurobehavioral Alterations and Brain Creatine Kinase System Changes in Chronic Renal Failure Induced Male Wistar Rats: Impact of Erythropoietin Supplementation. J Bioequiv Availab 7: $074-081$. doi:10.4172/jbb.1000218

Phase I:

\begin{tabular}{|c|c|c|c|}
\hline Parameters & Group 1 & Group 2 & Group 3 \\
\hline OA (sec) & $14.39 \pm 2.14$ & $6.50 \pm 1.05^{\star *}$ & $8.56 \pm 1.34^{*}$ \\
\hline CA (sec) & $55.33 \pm 3.73$ & $64.33 \pm 5.28 \mathrm{NS}$ & $56.33 \pm 4.01 \mathrm{NS}$ \\
\hline Centre (sec) & $30.28 \pm 1.77$ & $29.28 \pm 4.27 \mathrm{NS}$ & $35.06 \pm 4.73 \mathrm{NS}$ \\
\hline EOA (No.of times) & $6.33 \pm 1.11$ & $2.86 \pm 0.16^{*}$ & $3.50 \pm 0.42 \mathrm{NS}$ \\
\hline ECA (No.of times) & $4.67 \pm 0.55$ & $5.67 \pm 0.33 \mathrm{NS}$ & $6.91 \mathrm{NS}$ \\
\hline SAP (No.of times) & $4.17 \pm 0.66$ & $8.13 \pm 1.15^{\star *}$ & $5.97 \pm 0.8 \mathrm{NS}$ \\
\hline Rearing (No.of times) & $16.73 \pm 1.04$ & $29.83 \pm 1.24^{* *}$ & $5.00 \pm 0.57 \mathrm{NS}$ \\
\hline Grooming (No.of times) & $3.50 \pm 0.76$ & $6.15 \pm 0.51^{*}$ & $23.83 \pm 1.4 \mathrm{NS}$ \\
\hline Defecation (No.of times) & $1.43 \pm 0.7$ & $3.83 \pm 0.47^{*}$ & $3.83 \pm 0.6 \mathrm{NS}$ \\
\hline Head dips (No.of times) & $3.67 \pm 0.55$ & $9.09 \pm 0.81^{* * *}$ & $2.17 \pm 1.49 \mathrm{NS}$ \\
\hline
\end{tabular}

Phase II:

\begin{tabular}{|c|c|c|c|c|c|}
\hline Parameters & Group 1 & Group 2 & Group 3a & Group 3b & Group 4 \\
\hline $\mathrm{OA}(\mathrm{sec})$ & $17.19 \pm 1.14$ & $5.58 \pm 0.95^{\star \star *}$ & $5.61 \pm 1.07^{\star *}$ & $7.22 \pm 1.11^{\star \star}$ & $11.67 \pm 0.79^{*}$ \\
\hline $\mathrm{CA}(\mathrm{sec})$ & $53.27 \pm 3.28$ & $67.69 \pm 6.65 \mathrm{NS}$ & $65.17 \pm 5.21 \mathrm{NS}$ & $57.50 \pm 4.71 \mathrm{NS}$ & $45.67 \pm 3.47 \mathrm{NS}$ \\
\hline Centre (sec) & $29.51 \pm 2.03$ & $28.28 \pm 3.95 \mathrm{NS}$ & $29.39 \pm 4.24 \mathrm{NS}$ & $35.33 \pm 4.9 \mathrm{NS}$ & $42.67 \pm 2.68^{*}$ \\
\hline EOA (No.of times) & $5.33 \pm 1.27$ & $3.00 \pm 0.36 \mathrm{NS}$ & $2.67 \pm 0.42^{*}$ & $3.17 \pm 0.87 \mathrm{NS}$ & $6.17 \pm 0.7 \mathrm{NS}$ \\
\hline ECA (No.of times) & $3.27 \pm 0.71$ & $6.17 \pm 0.41^{*}$ & $5.17 \pm 0.3 \mathrm{NS}$ & $5.33 \pm 0.49 \mathrm{NS}$ & $4.13 \pm 0.26 \mathrm{NS}$ \\
\hline SAP (No.of times) & $3.67 \pm 0.45$ & $7.00 \pm 1.15^{*}$ & $9.17 \pm 0.6^{* * *}$ & $7.83 \pm 0.7^{\star *}$ & $7.33 \pm 0.55^{\star *}$ \\
\hline Rearing (No.of times) & $18.23 \pm 1.84$ & $31.83 \pm 1.08^{* *}$ & $32.17 \pm 2.38^{* * *}$ & $27.83 \pm 2.57^{*}$ & $22.77 \pm 1.31 \mathrm{NS}$ \\
\hline Grooming (No.of times) & $2.87 \pm 0.17$ & $5.45 \pm 0.44^{*}$ & $5.00 \pm 0.57 \mathrm{NS}$ & $5.33 \pm 0.49 \mathrm{NS}$ & $3.50 \pm 0.61 \mathrm{NS}$ \\
\hline Defecation (No.of times) & $1.83 \pm 0.3$ & $4.26 \pm 0.67^{*}$ & $3.50 \pm 0.42 \mathrm{NS}$ & $3.00 \pm 0.36 \mathrm{NS}$ & $4.17 \pm 0.61^{*}$ \\
\hline Head dips (No.of times) & $3.01 \pm 0.22$ & $9.17 \pm 0.94^{* * *}$ & $9.33 \pm 0.76^{\star * *}$ & $7.00 \pm 0.93^{*}$ & $4.00 \pm 0.73 \mathrm{NS}$ \\
\hline
\end{tabular}

Table 2: Effect of EPO on CRF induced behavioral changes is recorded by using plus maze in both phase I and phase II. Results are expressed as mean \pm SEM of 6 animals for each group; ${ }^{*} \mathrm{P}<0.05,{ }^{* *} \mathrm{P}<0.01,{ }^{* * *} \mathrm{P}<0.001$, NS - Not Significant; OA- Time spent in open arm, CA- Time spent in closed arm, centre - Time spent in the centre, EOA - Number of entry in open arm, ECA - Number of entries in closed arm, SAP - Stretch attending posture.

induced learning disability, as well as provided neuroprotection after traumatic brain injury [15] and spinal cord injury [40]. Some clinical studies also shown Epo treatment improved cognitive performance [41]. In patients with type I diabetes and hypoglycemia unawareness, treatment with Epo is associated with a beneficial effect on cognitive function in a complex reaction time task assessing sustained attention/ working memory $[42,43]$. In this study also, along with hematological parameters, neurobehavioral changes induced by CRF were retrieved after simultaneous and post treatment of Epo (Table 2 and Figure 5).

In this study, both simultaneous and post treatment of Epo protects creatine kinase system in CRF induced animals along with reduction in serum blood urea nitrogen and creatinine levels were observed. Several studies has postulated that Epo exerts its antioxidant effects through direct and indirect mechanism. The ATP binding domain of creatine kinase contains essential arginine, histidine, lysine, and cysteine amino acid residues that may be targeted by reactive oxygen species [44] and studies show the direct oxidation of sulfhydryl groups in cysteines located in the active site of creatine kinase may also inactivate the enzyme $[44,45]$. In this study the decreased creatine kinase activity in all the selected brain regions of CRF induced animals is retrieved after Epo treatment by its antioxidant role. Along with this benefit, neurobehavioral changes are improved, significantly in both the phases of Epo therapy.

\section{Conclusion}

The protective role of Epo supplementation on CRF induced changes in CK system in brain regions and serum and its correlation with neurobehavioral changes were seen. Herewith, we conclude that, along with anemic state and accumulation of uremic substances, the alterations of creatine kinase system in cerebellum, cerebral cortex and hippocampus is also one of the factor for neurobehavioral changes in CRF induced animals and Epo had an attenuating effect on adenine induced renal dysfunction. This study proves that Epo supplementation has a promising role in the behavioral response as well as in protecting brain creatine kinase system in CRF induced uremic animals.

\section{References}

1. Ali BH, Al-Salam S, Al Za'abi M, Waly MI, Ramkumar A, et al. (2013) New model for adenine-induced chronic renal failure in mice, and the effect of gum acacia treatment thereon: comparison with rats. J Pharmacol Toxicol Methods 68: 384-393.

2. Krishnan AV, Kiernan MC (2009) Neurological complications of chronic kidney disease. Nat Rev Neurol 5: 542-551.

3. Hossain MP, Goyder EC, Rigby JE, El Nahas M (2009) CKD and poverty: a growing global challenge. Am J Kidney Dis 53: 166-174.

4. Murray AM (2008) Cognitive impairment in the aging dialysis and chronic kidney disease populations: an occult burden. Adv Chronic Kidney Dis 15: 123-132.

5. Meyer TW, Hostetter TH (2007) Uremia. N Engl J Med 357: 1316-1325.

6. Sener G, Sakarcan A, Sehirli O, Ekshioglu-Demiralp E, Sener E, et al. (2007) Chronic renal failure- induced multiple-organ injury in rats is alleviated by the selective CysLT1 receptor antagonist montelukast. Prostaglandins Other Lipid Mediat 83: 257-267.

7. Carbonell T, Rama R (2007) Iron, oxidative stress and early neurological deterioration in ischemic stroke. Curr Med Chem 14: 857-874.

8. Hailpern SM, Melamed ML, Cohen HW, Hostetter TH (2007) Moderate chronic kidney disease and cognitive function in adults 20 to 59 years of age: Third National Health and Nutrition Examination Survey (NHANES III). J Am Soc Nephrol 18: 2205-2213.

9. Barinaga M (1997) What makes brain neurons run? Science 276: 196-198.

10. Tomimoto H, Yamamoto K, Homburger HA, Yanagihara T (1993) Immunoelectron microscopic investigation of creatine kinase BB-isoenzyme after cerebral ischemia in gerbils. Acta Neuropathol 86: 447-455.

11. Di- pietro PB, Dias ML, Scaini G, BurigoM,Constantino L, Machado RA, et al. (2008) Inhibition of brain creatine kinase activity after renal ischemia is attenuated by $\mathrm{N}$-acetylcysteine and deferoxime administration. Neuroscience letters 434: 139-143 
Citation: Karthick N, Alwin D, Poornima KN, Chitra V, Saravanan A, et al. (2015) Neurobehavioral Alterations and Brain Creatine Kinase System Changes in Chronic Renal Failure Induced Male Wistar Rats: Impact of Erythropoietin Supplementation. J Bioequiv Availab 7: $074-081$. doi:10.4172/jbb.1000218

12. Wolosker H, Panizzutti R, Engelender S (1996) Inhibition of creatine kinase by S-nitrosoglutathione. FEBS Lett 392: 274-276.

13. Aksenov M, Aksenova M, Butterfield DA, Markesbery WR (2000) Oxidative modification of creatine kinase BB in Alzheimer's disease brain. J Neurochem 74: $2520-2527$

14. Indumathy S, Kavimani S, Raman KV (2010) Role of angiotensin antagonists in memory enhancement. International Journal of Pharma and Bio Sciences 1: $1-6$

15. van der Kooij MA, Groenendaal F, Kavelaars A, Heijnen CJ, van Bel F (2008) Neuroprotective properties and mechanisms of erythropoietin in in vitro and in vivo experimental models for hypoxia/ischemia. Brain Res Rev 59: 22-33.

16. Brines ML, Ghezzi P, Keenan S, Agnello D, de Lanerolle NC, et al. (2000) Erythropoietin crosses the blood-brain barrier to protect against experimental brain injury. Proc Natl Acad Sci U S A 97: 10526-10531.

17. Brines M, Cerami A (2006) Discovering erythropoietin's extra-hematopoietic functions: biology and clinical promise. Kidney Int 70: 246-250.

18. Sola A, Wen TC, Hamrick SE, Ferriero DM (2005) Potential for protection and repair following injury to the developing brain: a role for erythropoietin? Pediatr Res 57: 110R-117R

19. Ozturk E, Demirbilek S, Kadir But A, Saricicek V, Gulec M, et al. (2005) Antioxidant properties of propofol and erythropoietin after closed head injury in rats. Prog Neuropsychopharmacol Biol Psychiatry 29: 922-927.

20. Bagnis C, Beaufils H, Jacquiaud C, Adabra Y, Jouanneau C, et al. (2001) Erythropoietin enhances recovery after cisplatin-induced acute renal failure in the rat. Nephrol Dial Transplant 16: 932-938.

21. Lee DW, Kwak IS, Lee SB, Song SH, Seong EY, et al. (2009) Post-treatment effects of erythropoietin and nordihydroguaiaretic acid on recovery from cisplatin-induced acute renal failure in the rat. J Korean Med Sci 24 Suppl: S170-175.

22. Salum C, Roque-da-Silva AC, Morato S (2003) Conflict as a determinant of rat behavior in three types of elevated plus-maze. Behav Processes 63: 87-93.

23. okinaka S, Sugita H, Momoi H, Toyokura Y, Watanabe T, Et Al. (1964) Cysteine-Stimulated Serum Creatine Kinase in Health and Disease. J Lab Clin Med 64: 299-305.

24. Hughes BP (1962) A method for the estimation of serum creatine kinase and its use in comparing creatine kinase and aldolase activity in normal and pathological sera. Clin Chim Acta 7: 597-603.

25. Bessman SP, Carpenter CL (1985) The creatine-creatine phosphate energy shuttle. See comment in PubMed Commons below Annu Rev Biochem 54 831-862.

26. Venkataraman P, Krishnamoorthy G, Selvakumar K, Arunakaran J. (2009) Oxidative Stress Alters Creatine Kinase System in Serum and Brain Regions of Polychlorinated Biphenyl (Aroclor 1254)-Exposed Rats:Protective Role of Melatonin. Basic \& Clinical Pharmacology \& Toxicology 105: 92-97.

27. Brouns R, De Deyn PP (2004) Neurological complications in renal failure: a review. Clin Neurol Neurosurg 107: 1-16.

28. Burn DJ, Bates D (1998) Neurology and the kidney. J Neurol Neurosurg Psychiatry 65: 810-821.

29. Babb AL, Ahmad S, Bergström J, Scribner BH (1981) The middle molecule hypothesis in perspective. Am J Kidney Dis 1: 46-50.

30. Thadhani R, Pascual M, Bonventre JV (1996) Acute renal failure. N Engl J Med 334: $1448-1460$

31. Singh AK, Szczech L, Tang KL, Barnhart H, Sapp S, et al. (2006) Correction of anemia with epoetin alfa in chronic kidney disease. N Engl J Med 355: 20852098.
32. Pisoni RL, Bragg-Gresham JL, Young EW, Akizawa T, Asano Y, et al. (2004) Anemia management and outcomes from 12 countries in the Dialysis Outcomes and Practice Patterns Study (DOPPS). Am J Kidney Dis 44: 94-111.

33. Foley RN, Parfey PS, Harnett JD, Kent GM, Murray DC, Barre PE (1996) The impact of anaemia on cardiomyopathy, morbidity and mortality in end stage renal disease. Am J Kidney Dis 28: 53-61.

34. 34. Katavetin P, Tungsanga K, Eiam-Ong S, Nangaku M (2007) Antioxidative effects of erythropoietin. Kidney international 72: S10-S15.

35. Pickett JL, Theberge DC, Brown WS, Schweitzer SU, Nissenson AR (1999) Normalizing hematocrit in dialysis patients improves brain function. Am J Kidney Dis 33: 1122-1130.

36. Zhu C, Kang W, Xu F, Cheng X, Zhang Z, et al. (2009) Erythropoietin improved neurologic outcomes in newborns with hypoxic-ischemic encephalopathy. Pediatrics 124: e218-226.

37. Zhang Y, Xiong Y, Mahmood A, Meng Y, Qu C, et al. (2009) Therapeutic effects of erythropoietin on histological and functional outcomes following traumatic brain injury in rats are independent of hematocrit. Brain Res 1294: 153-164.

38. Mogensen J, Miskowiak K, Sørensen TA, Lind CT, Olsen NV, et al. (2004) Erythropoietin improves place learning in fimbria-fornix-transected rats and modifies the search pattern of normal rats. Pharmacol Biochem Behav 77: 381 390.

39. Adamcio B, Sargin D, Stradomska A, Medrihan L, Gertler C, et al. (2008) Erythropoietin enhances hippocampal long-term potentiation and memory. BMC Biol 6: 37.

40. Celik M, Gökmen N, Erbayraktar S, Akhisaroglu M, Konakc S, et al. (2002) Erythropoietin prevents motor neuron apoptosis and neurologic disability in experimental spinal cord ischemic injury. Proc Natl Acad Sci U S A 99: 22582263.

41. Rasmussen $P$, Foged EM, Krogh-Madsen R, Nielsen J, Nielsen TR, et al (2010) Effects of erythropoietin administration on cerebral metabolism and exercise capacity in men. J Appl Physiol (1985) 109: 476-483.

42. Kristensen PL, Pedersen-Bjergaard U, Kjær TW, Olsen NV, Dela F, et al. (2013) Influence of Erythropoietin on Cognitive Performance during Experimental Hypoglycemia in Patients with Type1 Diabetes Mellitus: A Randomized CrossOver Trial. PLOS ONE 8: e59672.

43. Kristensen PL, Høi-Hansen T, Olsen NV, Pedersen-Bjergaard U, Thorsteinsson B (2009) Erythropoietin during hypoglycaemia in type 1 diabetes: relation to basal renin-angiotensin system activity and cognitive function. Diabetes Res Clin Pract 85: 75-84.

44. Koufen P, Stark G (2000) Free radical induced inactivation of creatine kinase: sites of interaction, protection, and recovery. Biochim Biophys Acta 1501: 4450 .

45. David S, Shoemaker M, Haley BE (1998) Abnormal properties of creatine kinase in Alzheimer's disease brain: correlation of reduced enzyme activity and active site photolabeling with aberrant cytosol-membrane partitioning. Brain Res Mol Brain Res 54: 276-287. 